\title{
PARTICIPAÇÃO COMUNITÁRIA: outras epistemologias
}

\author{
COMMUNITY PARTICIPATION: other epistemologies
}

\section{Rita de Cássia Fraga Machado}

\author{
Pertencer a uma comunidade significa renegar parte de nossa \\ individualidade em nome de uma estrutura montada para satisfazer nossas \\ necessidades de intimidade e da construção de uma "identidade. \\ (ZYGMUND BAUMAN, 2003, p.123)
}

\begin{abstract}
Resumo: Esse texto visa discutir outras epistemologias a partir da proposta de participação comunitária dos povos da Floresta Nacional de Tefé (Flona-Tefé). Durante essa caminhada de pesquisa e reflexão no interior do Amazonas, fui percebendo que o termo comunidade ocupa um lugar central. Quase tudo na vida da floresta se constrói por meio das comunidades e de forma comunitária, inclusive o processo de participação das mulheres. Partindo da perspectiva de que a participação comunitária e política feminina vêm aumentando nos últimos anos, principalmente devido ao acesso à educação, à formação e ao desejo de implementação de políticas públicas, da igualdade de gênero e salarial, o presente pretende mostrar, com base nos encontros e nas pesquisas realizadas com a comunidade da Flona-Tefé, as motivações e a satisfação da participação dessas mulheres na esfera pública.
\end{abstract}

Palavras Chave: Participação; Comunidade; Libertação; Gênero; Epistemologia.

\section{INTRODUÇÃO}

Durante nossa caminhada de pesquisa e reflexão no interior do Amazonas, fomos percebendo que o termo comunidade ocupa um lugar central nas discussões. Quase tudo na vida da floresta se constrói por meio das comunidades, e de forma comunitária, inclusive o processo de participação das mulheres no mundo público. $\mathrm{O}$ comum² é o modo de vida dessas populações, ou seja, o bem comum. A comunidade não é um corpo ou um objeto, mas uma construção ideológica que se baseia na necessidade singular da segurança, do conforto, da familiaridade e do sentimento de pertencimento, isto é, de que fazemos parte de algo maior que nossa individualidade; a delimitação entre o "Nós" (o familiar) e os "outros" (o estranho) ocorre sem perder a conexão com a coletividade (totalidade). (BAUMAN, 2003)

Nas comunidades, as identidades se reinventam num fazer-se e viver-se coletivo. Tudo parece assumir outro sentido para os sujeitos que a elas pertencem. As individualidades estão ali, mas

\footnotetext{
${ }^{1}$ Professora de Filosofia da Universidade do Estado do Amazonas - UEA. E-mail: <rmachado@uea.edu.br>

${ }^{2}$ Comum aqui significa o que é de todos, mesmo que um tenha adquirido. Aqui, o uso qualitativo do tempo na forma comunal de intercâmbio reprodutivo representa o nível historicamente atingível e, nas fases mais avançadas do socialismo, o único e absoluto modo de mediação dos produtores associados. (MESZASROS, 2009)
} 
recheadas de práticas comuns. A comunidade é uma unidade que expressa um núcleo único e revelador de modos de vida. Diante de tanta precariedade da existência, as estratégicas de sobrevivência passam pela solidariedade e pela união das pessoas. Assim, a comunidade é um núcleo estável que "ocupa de las ambivalências actuales do individualismo moderno, signado pela la tension mencionada entre segurid e liberdad" (CARILLHO, 2014, p. 93).

A liberdade, para estas comunidades, significa que todas as pessoas poderão desfrutar do bem comum. Desta forma, a noção de liberdade se contrapõe à liberdade de mercado, aquela que traz um imaginário falso de conquista e segurança. Na comunidade, a segurança é real e a liberdade é o que dá sentido às ações. A atividade dos seres não é desconectada da sua natureza, os sujeitos encontram-se numa sociedade natural, onde a cisão entre os-interesses não aparece na produção do bem comum.

O que chamamos de identidades não se individualiza na atividade total. Tal atividade é divida voluntariamente, o que converte para um poder comunitário, dominado pelos próprios comunitários. Assim, afirmamos que há uma realização plena, que não expropria trabalho nem riqueza. E com essas constatações, faz-se necessário que olhemos para esses dispositivos numa nova distinção social.

Para Redfiel, la comunidad requiere ser distintiva con relación a otros grupos humanos, pequeña, como para que todos sus miembros estén a la vista uno com otros, y autosificiente: una comunidad esos rasgos, una comunidad no se siente convocada por la reflexion, la crítica o la innovación. (CAMILO, 2014, p. 92)

A interferência do mundo exterior provoca muitas ambiguidades existenciais, e a escola é o maior canal dessa interferência. São diferentes modos de vida que tentam ser introduzidos pela sociedade contemporânea. A interferência desse mundo exterior é muito forte, mas há o que se chama de resistência. E esta convida os comunitários à reflexão, conduzindo-os, para que todos possam ter um mesmo entendimento do que resistir significa na sua vida comum, sem perder suas individualizações, tais como valores, normas, costumes, alimentação, crença, vestimenta, etc.

Dessa maneira, concordamos com Agamben (2013) de que, sem a individualização, não é possível pensar o singular e, por sua vez, o comum, de forma dialética.

É sabido como a escolástica coloca o problema do principium individuationis: face a Tomás que procura seu lugar na matéria" (...) concebe, ao contrário, a individualização como o acrescentar-se a natureza ou forma comum (por exemplo a humanidade) não de uma forma ou essência ou propriedade, mas de uma ultima realitas, de uma "ultimidade" da própria forma. A singularidade não acrescenta nada a forma comum. (...) "não se oponha a ser colocada como uma unidade singular qualquer que seja" [...] O ter-lugar, o comunicar das singularidades no atributo da extensão, não as une na essência, mas as dispersa na existência. (AGAMBEN, 2013, p, 25)

Com isto, para Agamben (2013, p. 27) "a in-diferença com respeito às propriedades é o que individua e dissemina as singularidades, as torna amáveis (quodlibertais). Essa da natureza", do comum. Do mesmo modo, o rosto humano não é nem o um individualizar-se de uma face genérica, nem o universalizar-se de traços singulares: é rosto qualquer, no qual, o que pertence à natureza comum e o que lhe é próprio são absolutamente indiferentes.

Bauman, em Comunidade a busca por segurança no mundo atual (2003), faz uma observação sobre os conceitos teóricos e clássicos sobre a comunidade, de forma geral, para, então, entrar na reflexão sobre comunidades hoje existentes. Sentimos falta, nestas reflexões, das comunidades reais da Amazônia, tendo em vista que, neste território, encontramos a forma mais antiga de viver em comunidade. Mas, como todo intelectual contextualiza suas análises, compreendemos de qual lugar fala Bauman. Ou seja, como mesmo expressa o autor, "a comunidade de entendimento comum, mesmo se alcançada, permanecerá, portanto frágil e vulnerável, precisamos para sempre de vigilância, reforço e defesa". (BAUMAN, 2003, p. 19). 
A promoção da segurança, segundo ele, sempre requer o sacrifício da liberdade, enquanto esta só pode ser ampliada à custa da segurança. Mas a segurança sem liberdade equivale à escravidão (e, além disso, sem uma "injeção" de liberdade, acaba por ser, afinal, um tipo muito inseguro de segurança); e a liberdade sem segurança equivale ao sentimento de perda e abandono (e, no limite, sem uma "injeção" de segurança, acaba por ser uma liberdade muito pouco livre). Esse debate provoca nos filósofos uma dor de cabeça sem cura conhecida. Ele também torna a vida em comum um conflito sem fim, pois a segurança sacrificada em nome da liberdade tende a ser segurança dos outros, e a liberdade sacrificada em nome da segurança tende a ser liberdade dos outros. (BAUMAN, 2003, p. 24)

\section{A PARTICIPAÇÃO E SUA IMPORTÂNCIA NA COMUNIDADE}

Que "o interesse por participar da vida política tem se generalizado nos últimos anos, no Brasil e no mundo todo, não resta a menor duvida," (BORDENAVE, 1983 p.7). Com isso, a todo o momento, surgem novas associações, dos mais diversos tipos, como as ecológicas, associações de moradores, comunidades eclesiais, etc. E desta forma, a participação política em tais associações significa comunicar, isto é, participar, abrindo um mundo de possibilidades para a descoberta dos seus direitos, aprendendo sobre o mundo de diversas formas.

Podemos designar a "participação como aspirações de setores cada vez mais numerosos da população assumindo o controle do próprio destino" (BORDENAVE, 1983, p.8), em que se destaca a luta diária das mulheres, a exemplo das brasileiras, reivindicando seus direitos e políticas públicas, melhores condições de vida, acesso à educação e à voz. Portanto, falar sobre a trajetória de participação das mulheres brasileiras é tratar de conquistas de direitos, de espaços públicos para sua atuação. É também abordar as mudanças ocorridas na sociedade, que fizeram com que a mulher deixasse de ter apenas o lar como palco de atuação e passasse a estar presente também nas escolas e universidades, no mercado de trabalho, nos mais variados tipos de associações e comunidades bem como em sindicatos e nos órgãos políticos em geral. Enfim, em todas as instâncias sociais.

Se Maria Antonieta foi uma rainha escandalosa, não só porque traia o Rei (a corte já vira outras e não era tão pudica), mas sim porque ela mostrava novas concepções nas relações de público e privado. Por um lado, essa mulher estrangeira intervinha nos negócios do Reino. Por outro, ela exigia uma espaço próprio, subtraindo o olhar de todos, para dedicar-se ali seus prazeres, receber seus íntimos e experimentar as alegrias das amizades. (PERROT, 2005, p. 455)

A participação está na ordem do dia das comunidades devido ao "descontentamento geral com a marginalização do povo dos assuntos que interessam a todos (as), e que são decididos por poucos" (BORDENAVE,1983 p.12). Ao procurar compreender a motivação dos participantes de uma atividade comunitária, qualquer que seja o tipo de participação, nota-se uma satisfação pessoal e íntima que, com frequência, vai muito além dos resultados obtidos pela sua participação individual, pois diz respeito às identidades coletivas ali inventadas.

Bauman retoma a Hobsbawm para quien las investigaciones a la comunidad, coinciden con su exteción empírica y que las identidades se inventan cuando colapsan las comunidades. La precariedade de indentidades individuales lleva que las personas acudan a las "comunidades perschas" para encontrar en ellas la seguridad anhelad, en compañia de otros igualmente temerosos. Retomando a Stuart Hall, Bauman afirma que estas identidades no expresan un núcleo estable del yo, sino discripiciones estratégicas y precárias (CARRILHO apud BAUMAN, 2014, p. 93)

Assim, "do ponto de vista dos setores progressistas, a participação facilita o crescimento da consciência crítica da população, fortalece seu poder na sociedade". (BORDENAVE, 1983, p. 12). Entretanto, o tema da participação feminina na vida pública e comunitária ainda é pouco debatido nas esferas públicas de nossa sociedade. Haja vista as poucas mulheres que exercem cargos na política, em instituições eclesiásticas e científicas e na comunidade. Fato é que, mesmo nestes espaços, as mulheres 
enfrentam diariamente o conservadorismo dos "bons costumes" e da moral impostos pelo patriarcado à sociedade brasileira.

Sabemos que a participação política das mulheres no Brasil por meio do voto é recente: somente em 1932, as mulheres conquistaram o direito de votar e também puderam se candidatar a cargos políticos. A partir disso, avançamos rápido e, em 1933, tivemos a primeira Deputada Federal brasileira, Carlota Pereira de Queirós. Mas, somente com a constituição 1934, os direitos políticos conferidos às mulheres foram assentados em bases constitucionais, porém restringindo a votação às mulheres que exerciam função pública remunerada.

Para Bordenave (1983, p. 73),

A vantagem da participação é que, estas coisas não se adquirem numa sala de aula, mas na chamada práxis, que é o processo que mistura a prática, a invenção e a teoria, colocando-as ao serviço da luta pelos objetivos do povo.

Como aponta o autor, a participação é um processo que mistura a prática e a teoria e se coloca a serviço da luta. Desta forma, o direito à participação sempre motivou mulheres, as quais, em 1946, conseguiriam votar efetivamente, diante de todo impedimento durante o período da Ditadura de Getúlio Vargas, - durante esse período, o direito ao voto foi diluído, uma vez que as liberdades constitucionais "foram suspensas".

Como aponta Garcia (2000, p.18), "a luta pela construção de uma sociedade mais justa, solidária, igualitária se inclui a luta pelo direito de participar". Com isso, torna-se importante a superação da subalternização, recuperando um alto conceito positivo, individual e coletivo, um sentimento de potência. Ainda, segundo Garcia (2000), os movimentos sociais, como tema central de uma reflexão sobre a mudança, constituem um objetivo que atravessa diversos campos de força e espaços simbólicos que dão suporte à trama da vida social.

No que diz respeito aos diretos humanos em relação às mulheres, encontramos diversas instituições que se engajaram no movimento feminista pela luta por igualdade de oportunidades e pelo direito à participação como meio de chegar às ampliações de consciências.

Uma conquista feminina importante no âmbito da política e da participação foi a adoção de cotas para candidatura de mulheres nos partidos políticos, medida que busca criar condições para o estabelecimento de maior equilíbrio entre homens e mulheres no plano da representação política. Num primeiro momento, foram medidas compensatórias que "possibilitam" que mais mulheres ocupem os espaços políticos. Num segundo, são medidas distributivas que buscam assegurar a "igualdade" entre homens e mulheres.

Como aponta Rangel (2014, p. 34), "A constante exclusão das mulheres dos espaços políticos de poder tem sido objeto de interesse da comunidade internacional". Neste sentido, a autora vai afirmar que a IV Conferencia Mundial de Mulheres (Pequim, 1995) recomendou duas estratégias para alcançar a igualdade de gênero através da participação:

A $1^{\circ}$ a transversalidade em todos os processos de tomadas de decisões, e a $2^{\circ}$, o empoderamento das mulheres entendidas como a autoafirmação das capacidades das mulheres para sua participação, em condições de igualdade, nos processos de tomada de decisão e de acesso ao poder (RANGEL, 2014, p. 34).

\section{A PARTICIPAÇÃO E A COMUNIDADE}

Sobre o debate atual acerca da relação entre participação e comunidade, é importante a pontuação de Carrilho (2014) quando afirma que:

Este "sintonia comunitário", em SUS múltiples expressiones sociales, culturales e políticas, convocó desde la década de los ochentas del siglo XX a diferentes pensadores y estudiosos de la sociedade de países metropolitanos. En primero lugar, como ya se dijo, en el mundo acadêmico anglosajón comezó el debate 
entre filósofos liberales e comunitarista, cuya preocupacion e debate era defender La melhor maneira como a democracias republicanas podiam aborda y direcionar as co existências dentro de las sociedades de diferentes grupos humanos con tradiciones, modos de vida e cosmovisonaes diversas. Esa cuestión convoco a importante pensadores norte americanos y europeus como Rawl (1979, 1986 y 1996), Walzer (1983), Taylor (1993), Dworkin (1996), Rorty (1992), Etzioni (2001), Thiebaut (1992) y Camps (1993). (CARRILHO, 2014, p. 23)

Desta forma, ao longo da investigação ${ }^{3}$ realizada com a comunidade da Floresta Nacional de Tefé (Flona-Tefé), cujo objetivo era discutir como a participação torna-se um dispositivo pedagógico na emancipação dessas no processo de democratização da comunidade, percebeu-se, através da lista de presença do encontro e das intervenções em espaços como conselhos representativos, o aumento da participação e envolvimentos das mulheres nos encontros de pesquisa e formação. E os temas e local de cada reunião eram escolhidos por elas. Nesse momento - as reuniões -, elas também se voltam para o encontro, enquanto a comunidade prepara a alimentação e a infra-estrutura do mesmo. A participação ali se dá de forma comunitária, toda a comunidade se organiza em torno de um único objetivo: o encontro das mulheres da Flona. São crianças, adolescentes, mães, esposos, todos (as) num único ambiente.

Foto 1 - Encontro de Formação/Todas pelo bem comum

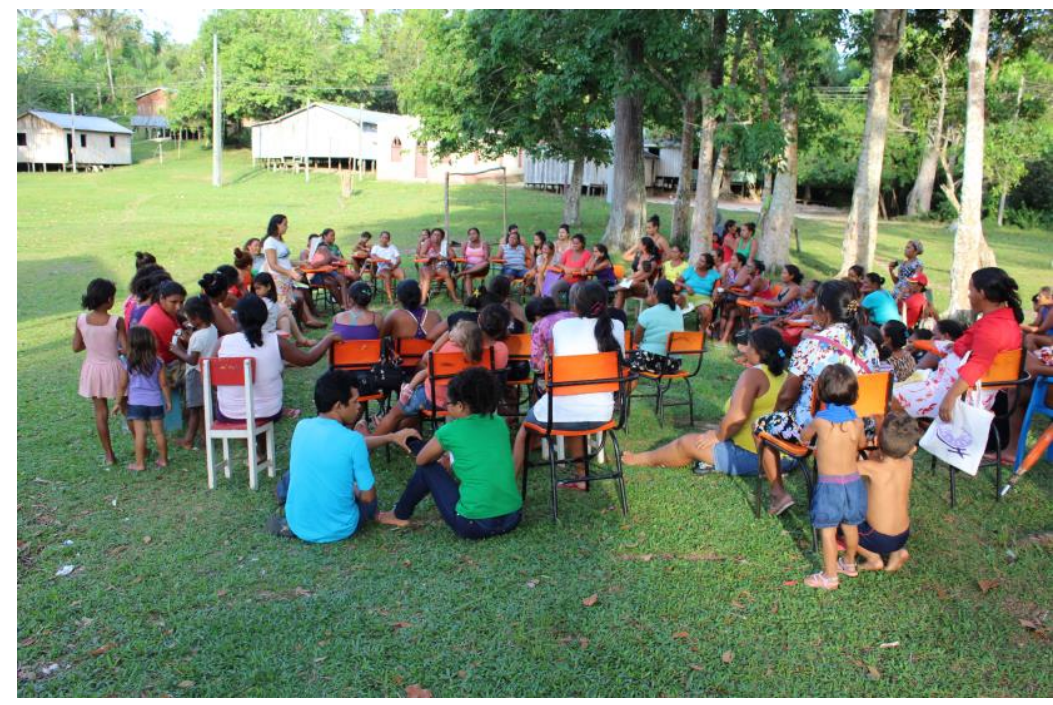

Foto: Sergio Luis, 2016.

Fonte: Arquivo de pesquisa.

Não há dúvidas que, comparado à situação de décadas atrás, o grau de participação das mulheres aumentou nos espaços públicos, sobretudo nas associações comunitárias. Percebe-se que as mulheres estão mais autônomas, organizando-se para participarem de eventos em seu ambiente local, dos quais antes nem imaginavam participar. E atualmente também participam de Conferências e Marchas Mundiais ligadas às diversas questões em seu favor.

Percebe-se o avanço nas questões de mobilização e organização dessas mulheres da FLONA em comunidade. Visto que antes elas só participavam, timidamente, de alguns espaços destinados a elas, como a casa, hoje ampliam seus espaços de atuação, participando do Conselho Municipal da Mulher (CFFT) como Conselheiras.

\footnotetext{
${ }^{3}$ Realizamos uma pesquisa que envolve mulheres da floresta e participação, essa tem o objetivo de discutir como a participação torna-se um dispositivo pedagógico na emancipação dessas no processo de democratização da comunidade.
} 
O gráfico abaixo, de participação das mulheres no Conselho Deliberativo das Comunidades, mostra que a participação das mulheres vem aumentando desde 2012, quando iniciamos a pesquisa, nestes espaços.

\section{Grafico 1 - Participação em 2017.}

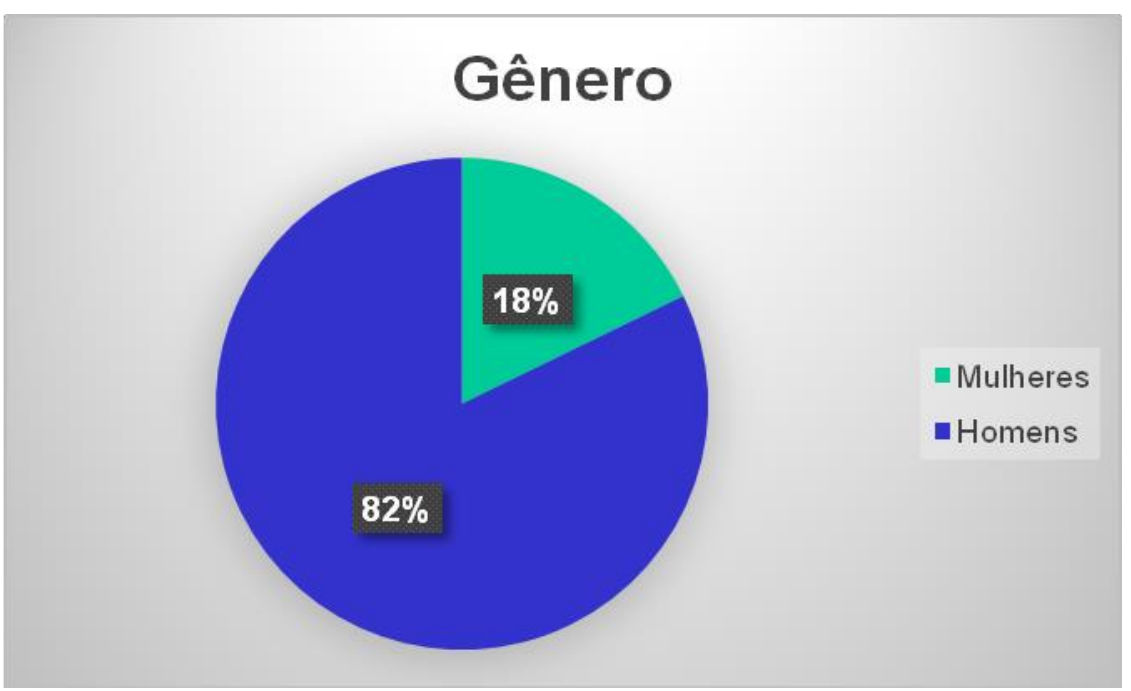

Fonte: Instituto Chico Mendes de Preservação - UC Tefé

Tendo em vista ainda a pouca participação das mulheres nas tomadas de decisão, a formação/ educação é essencial para promover a "igualdade" de gênero nas comunidades ribeirinhsa da Flona de Tefé, onde a má qualidade da Educação é um problema grave. Entretanto, o envolvimento das mulheres em cada encontro é perceptível, e isso significa, sobretudo, o enfrentamento dos próprios desafios na luta por igualdade, participação política, transformando a sociedade em que estão inseridas em busca de igualdade de gênero e de renda, com capacidade de assumir papéis para além do trabalho doméstico e do extrativismo. Um exemplo dos desafios enfrentados é o fato dessas mulheres deixarem de frequentar a escola, sem mesmo terem adquirido conhecimentos básicos (escolarização), devido ao casamento e ao trabalho doméstico.

Tabela 1 - Síntese do perfil das entrevistadas

\begin{tabular}{|c|l|r|}
\hline Questão & Alternativas & Percentual \\
\hline \multirow{3}{*}{ Idade } & De 17 a 30 anos & $46,34 \%$ \\
& De 31 a 40 anos & $24,4 \%$ \\
& De 41 a 50 anos & $14,63 \%$ \\
& Acima de 50 anos & $14,63 \%$ \\
\hline & Não alfabetizada & $7,31 \%$ \\
& Alfabetizada & $26,83 \%$ \\
& Ensino Fundamental incompleto & $14,63 \%$ \\
& Ensino fundamental completo & $17,1 \%$ \\
& Ensino médio incompleto & $14,63 \%$ \\
& Ensino médio completo & $12,2 \%$ \\
& EJA & $7,31 \%$ \\
\hline \multirow{2}{*}{ Está estudando atualmente } & Não & $65,9 \%$ \\
& Sim & $34,1 \%$ \\
\hline \multirow{3}{*}{ Estado civil } & Casada & $41,5 \%$ \\
& Solteira & $9,8 \%$ \\
& Viúva & $2,44 \%$ \\
& União estável & $46,34 \%$ \\
\hline
\end{tabular}

Fonte: Banco de dados da pesquisa do grupo de pesquisa. 
Como muitas delas não são alfabetizadas, sentem-se despreparadas para enfrentar e reivindicar seus direitos bem como para participar politicamente na comunidade, nas reuniões setoriais da Unidade de Conservação e nas Assembléias. É perceptível que, à medida que elas se casam, a escola vai sendo deixada de lado e a casa se torna seu único espaço de "participação".

Ao longo dos encontros, fomos observando como o patriarcado e o machismo ali existentes têm predominado fortemente, mesmo com todo o trabalho de formação realizado. As mulheres passam mais tempo cuidando dos filhos e realizando os trabalhos domésticos do que participando de outro ambiente que não seja o do lar e da família. Uma tabela que também nos ajuda a perceber essas questões é a que segue:

Tabela 2. Existência de filhos e quantidade

\begin{tabular}{|c|l|r|}
\hline Questão & Alternativas & Percentual \\
\hline \multirow{2}{*}{ Possui filhos } & Sim & $97,6 \%$ \\
& Não & $2,4 \%$ \\
\hline \multirow{5}{*}{ Quantos Filhos } & 1 a 2 filhos & $29,3 \%$ \\
& 3 a 4 filhos & $24,4 \%$ \\
& 5 a 6 filhos & $22 \%$ \\
& 7 a 12 filhos & $24,4 \%$ \\
\hline
\end{tabular}

Fonte: Banco de dados da pesquisa do grupo de pesquisa.

Com isso, ao longo da pesquisa, percebemos que a Formação/ Educação ainda é o caminho para o desenvolvimento e é a forma de instruí-las para poderem reivindicar os seus direitos e terem resultados positivos, como mulheres emancipadas que participam da vida comunitária, como um todo.

As tarefas destinadas às mulheres da Flona, segundo elas próprias, "são mais árduas tendo de cuidar dos filhos, enquanto os homens frequentam algum tipo de lazer como esportes ou brincadeiras que compensem o tempo que trabalhou durante o dia" (Relato Oral).

\section{OS DESAFIOS DO TRABALHO FORMATIVO}

Este trabalho realizado com as mulheres da Flona foi visto num primeiro momento como um grande desafio porque, ao se tratar de uma região onde o acesso é apenas fluvial, o desenvolvimento de trabalhos mais efetivos encontra várias dificuldades de uma formação contínua, pois conta com menores intervalos de tempo.

Tais desafios nos incentivaram a levantar questões e conhecimento acerca dessas mulheres, os quais dificilmente aparecem nas estatísticas elaboradas pelas instituições. Diariamente elas enfrentam violências de formas variadas: trabalhando e "pegando duro" no sol e na roça, cuidando da floresta, preservando os rios, a mata, os animais e sua comunidade. A busca pelo bem comum é algo estruturante na vida das comunidades, "(...) a busca daquilo que propicia a boa convivência que inclui as pessoas se impõem (...) estamos defendendo florestas e rios, povos primitivos, e as mulheres da floresta. Estamos abrindo espaços, para novas formas de justiça e direito das mulheres". (GEBARA, 2016 p. 198)

A educação Popular parece se alargar para além de nossos limites geográficos. O povo é bem mais que o meu povo, o mundo mais do que minha cidade, a casa comum mais do que a minha casa. Há algo de ilimitado que se descortina, de mais amplo, de maior do que meu pequeno universo e minhas reivindicações embora elas guardem sua importância e seu valor. A solidariedade alarga a sua tenda. (GEBARA, 2016, p. 198) 
Entendemos que há um sentimento em todas as mulheres de reinventarem as relações na comunidade. Uma "aventura do comum", como diz Gebara. Não sei se estamos reinventando a humanidade ou se somos capazes disso, dado o alto grau destrutivo do capital em relação aos bens comuns.

Por sua vez, Harribey (2014, p. 21) explica que "[...] o valor do estoque de recursos naturais é inestimável em termos econômicos [...], uma vez que tais recursos condicionam a vida da espécie humana”. Isso significa que ele não pode ser reduzido a uma categoria econômica. Sem a natureza, o homem não pode produzir qualquer coisa, nem em termos físicos nem em termos de valor econômico. A atividade econômica se insere necessariamente em relações sociais e numa biosfera. Não se pode dispensar a natureza para produzir coletivamente valor de uso, e não se pode substituíla indefinidamente por artefatos.

Foto 2 - Encontro de Formação/Todas pelo bem comum

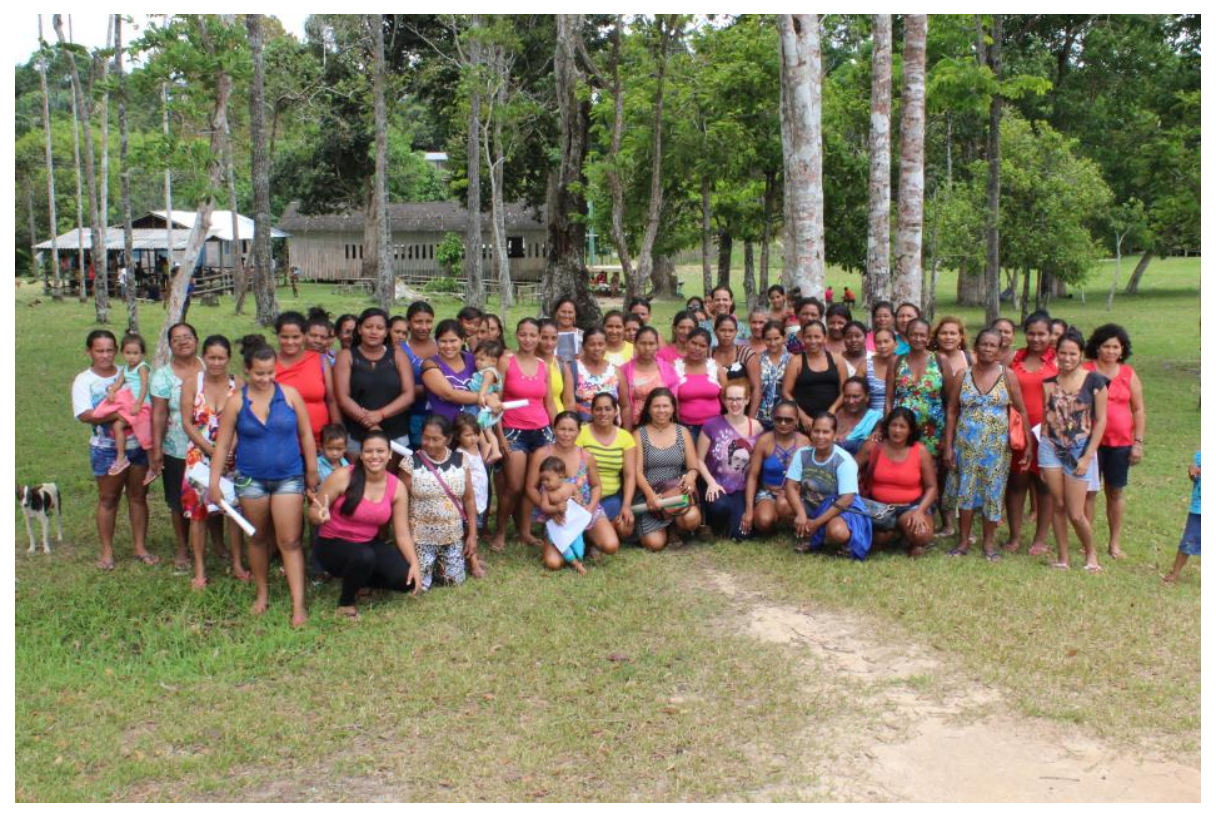

Foto: Sergio Luis, 2016.

Fonte: Arquivo de pesquisa.

A gratidão de estarem todas juntas em reflexão sobre o espaço que querem continuar construindo é sempre o começo para pensar o mundo, a comunidade e a elas mesmas como uma novidade que elas próprias criam, cotidianamente.

\section{A PESQUISA E SUAS CONTRIBUIÇÕES}

Conhecida como uma pesquisa-ação participante objetiva a construção do conhecimento através do método materialista histórico, esse processo se dará com e entre os próprios integrantes deste movimento, buscando identificar $e$ formular seus problemas, levantar propostas e alternativas, de acordo com seus interesses de classe, o que nos ajuda neste trabalho (MACHADO 2015, p, 30 destaque nosso).

Nas reuniões da Flona, as elaborações para a construção do conhecimento possibilitaram a compreensão e ajudaram a perceber que a cada encontro novas reflexões surgiam a partir das discussões dos temas. Ao longo dos encontros, percebia-se nas falas e nas conversas informais o quanto as mulheres estavam satisfeitas por estarem participando, conhecendo seus direitos, tomando decisões importantes junto às lideranças das comunidades em que vivem:

"Eu queria falar para as mulheres que não desistam da nossa união porque, quando se fala de movimento de mulheres os homens não querem que isso 
aconteça, mas nós estamos lutando pelos nossos direitos e objetivos" (registro de uma mulher da Flona no diário de campo).

Assim, cada tema discutido nos encontros partiu das necessidades das mulheres, ou seja, escolhidos por elas mesmas. Nas conversas informais, depois de realizada a programação destacada para o dia de encontro com elas, foi possível perceber a troca de idéias. A educação dessas mulheres, em processo de organização, está ligada a uma concepção de projeto amplo de sociedade e transformação, como aponta Paludo (2001):

A educação como prática social instituída, independente dos espaços onde ocorra e dos sujeitos que a realizam, sempre esteve indissociada da perspectiva da construção de um projeto em disputa e da direção dos processos de desenvolvimento na sociedade. Portanto, sempre estiveram intrinsecamente ligadas e dialogando com o movimento sociocultural, político e econômico mais amplo de forças vivas que lhe dão sustentação e colocam em movimento. (PALUDO, 2001, p. 181)

Nos dados obtidos, observou-se que a maioria das mulheres da Flona trabalha também "fora" de casa, no roçado, e, ao voltarem para casa, cuidam dos filhos, lavam roupa, preparam os alimentos e ainda estudam durante a noite. Desta forma, as mulheres da Flona e do seu entorno realizam uma tripla jornada de trabalho: a responsabilidade com a família, o trabalho e o estudo.

O fenômeno da exploração aparece, pois, escamoteado. Parece não existir, uma vez que ninguém extrai mais valia do trabalho doméstico da mulher. Entretanto, é perceptível, se analisarmos o trabalho doméstico da mulher através do circuito que se estabelece o capital e a família por intermédio do trabalho produtivo do homem. [...] evidentemente, este processo é vantajoso para o capital, mas apresenta conseqüências extremamente deletérias para as mulheres. (SAFIOTTI, 1984, p. 21).

Como afirma Safiotti, o trabalho doméstico acaba sendo vantajoso para o capital, pois não se é remunerado, já que é concebido por muitas mulheres como tarefas obrigatórias e não como trabalhos. Ao longo da execução do projeto com as mulheres da Flona, percebeu-se o aumento da sua participação e envolvimento nos encontros de formação. A partir das discussões dos temas e do local escolhido, ao final de cada encontro, as conversas sempre se voltavam para questão do trabalho feminino e para a ausência de participação dos seus maridos.

Outra questão importante foi perceber que o envolvimento dessas mulheres nos eventos demonstra a satisfação que estavam sentindo em participar, visto que antes sequer imaginavam sair das suas casas, de suas comunidades. A participação feminina (que antes se dava apenas na cozinha) nas assembléias e na Associação já se estende além das plenárias e decisões. Vemos também elas assumirem cargos da diretoria e como conselheiras. E no lugar de discursos tímidos, vemos hoje mulheres articuladas, programando-se coletivamente, tomando decisões importantes dentro das comunidades e qualificando suas vidas pela participação.

Portanto, os exemplos apresentados, com base no nosso referencial teórico, confirmam a premissa de que a vida comunitária possibilita o viver comum e de como a participação das mulheres tem democratizado as comunidades na realização de um direito humano universal. Entretanto, alguns desafios ainda estão postos, pois encontramos nessas comunidades tentativas de privatização que seguem um padrão global de avanço das relações capitalistas, para esferas que dizem respeito à persecução de direitos humanos, e que tocam muito diretamente os direitos à vida e à dignidade das mulheres, mas essas mulheres ainda são ambivalentes.

\section{REFERÊNCIAS}

AGAMBEN, Giorgio. A comunidade que vem. Tradução e notas Claúdio Oliveira. Belo Horizonte: Autêntica Editora, 2013. 
BAUMAN, Zygmunt, 1925-Comunidade: a busca por segurança no mundo atual. tradução Plínio Dentzien. — Rio de Janeiro: Jorge Zahar Ed., 2003.

BORDENAVE, Juan E. Díaz, O que é participação, $6^{\circ}$ ed, Brasiliense, São Paulo, 1995.

CARRILHO, Afonso T. El retorno a La comunidad: problemas, debates y desafios de vivir juntos. Fundação centro deducação y Desarrollo Humano- CINDE. Editora El Búho Ltda, 2014.

MESZÁROS, Isteván. Para além do Capital. Boitempo Editorial, 3 reimpressão, 2009.

MACHADO, Rita de Cassia. Estudos Feministas, mulheres e Educação Popular. 1. ed. Curitiba: CRV, 2016.

SAFFIOTI, Heleieth I. B. O Poder do Macho. São Paulo: Moderna, 1987.

HARRIBEY. Jean-Marie. Criar riqueza, não valor. Le Monde Diplomatique Brasil. Ano 7, n. 79. Fev. 2014. p. 20.21. 